D.O.I.: $10.3895 / \mathrm{S} 1808-04482010000400005$

\title{
OTIMIZAÇÃO DE LAYOUT UTILIZANDO-SE O SLP COMBINADO COM TEORIA DAS FILAS: UM ESTUDO DE CASO EM UMA OFICINA DE RODAS E FREIOS DE AERONAVES
}

\section{LAYOUT OPTIMIZATION USING COMBINED SLP AND QUEUEING THEORY: AN AIRPLANE WHEELS \& BRAKES WORKSHOP CASE STUDY}

\author{
Lino G. Marujo ${ }^{1}$; Diego Carvalho ${ }^{2}$; Mauricio N. Leitão ${ }^{3}$ \\ ${ }^{1}$ CEFET-RJ - Brasil \\ linomarujo@cefet-rj.br \\ ${ }^{2}$ CEFET-RJ - Brasil \\ dcarvalho@ieee.com \\ ${ }^{3}$ CEFET-RJ - Brasil \\ mnleitao@gmail.com
}

\begin{abstract}
Resumo
Este trabalho analisa a aplicação do SLP - systematic planning layout em conjunto com a teoria das filas como forma de complementar uma metodologia já consagrada. Foi desenvolvido um projeto de readequação do layout de uma oficina de rodas e freios de equipamentos de transporte de massa, buscando avaliar a aplicabilidade da metodologia em conjunto com técnicas de modelagem de teoria de filas. A partir do estudo de caso real foi possível identificar os recursos que limitam a capacidade de entrega de todo o sistema da oficina, donde se concluiu que, mesmo com capacidade ociosa em alguns postos de trabalho, o aumento de recursos é necessário e deve ser direcionado para o recurso tido como gargalo.
\end{abstract}

Palavras-chave: oficina; otimização de layout; SLP; teoria de filas.

\section{Introdução}

O arranjo físico (layout) de uma operação produtiva preocupa-se com o posicionamento físico dos recursos de transformação. Em outras palavras, definir o arranjo físico é decidir onde colocar as instalações, máquinas, equipamentos e pessoal da produção. É uma das características mais evidentes de uma operação produtiva, pois determina sua forma e aparência. $\mathrm{O}$ arranjo físico determina também a maneira segundo a qual os recursos, sejam estes materiais, informações, clientes, etc. fluem pela operação.

O layout de uma fábrica é produto de milhares de decisões, passadas e presentes. É a manifestação física da estratégia de produção da empresa (LEE QUARTERMAN, 1998). 
A maioria dos arranjos físicos em termos práticos é derivada de apenas quatro tipos básicos de arranjo, a saber: arranjo físico posicional, arranjo físico por processo, arranjo físico celular, arranjo físico por produto (SLACK; NIGEL, 2002).

O arranjo físico por produto envolve localizar os recursos produtivos transformadores inteiramente segundo a melhor conveniência do recurso que está sendo transformado. Cada produto, elemento de informação ou cliente segue um roteiro predefinido no qual a seqüência de atividades requerida coincide com a seqüência nas quais os processos foram arranjados fisicamente. Por esse mesmo motivo esse arranjo físico costuma ser chamado de arranjo físico em fluxo ou em linha. O fluxo de produtos, informações ou clientes é muito claro e previsível no arranjo físico por produto, o que faz dele um arranjo relativamente fácil de controlar. Predominantemente, é a uniformidade dos requisitos que leva a operação a escolher um arranjo físico por produto (TOMPKINS et al, 2003).

As vantagens da seleção do arranjo físico por produto são os baixos custos unitários para altos volumes, oportunidade para especialização de equipamentos e uma movimentação conveniente de materiais. Suas desvantagens de acordo com nossa dedução são: a baixa flexibilidade e a pouca robustez contra interrupções, além de tornar o trabalho repetitivo.

Alguns modelos podem ser adotados para tal. Chin e Gonçalves Filho (2008) utilizaram uma técnica de coloração de grafos para o detalhamento das fases de estudo e desenvolvimento de um layout do tipo job-shop. Outro artigo faz uma varredura na literatura de aplicações do Problema Quadrático de Alocação (QAP, em inglês) para otimização estática de layouts, apresentando um estudo de caso para a otimização do layout de um centro de distribuição de produtos siderúrgicos (MARUJO, 2009).

\section{O processo de reparos de rodas e freios de aeronaves}

O processo de reparos ou revisão de rodas de aeronaves se assemelha ao modelo de processo de produção em massa, pois apesar do volume não ser tão alto como o nome do processo dá a entender, outras características muito importantes correspondem a esse tipo de processo, como a variedade relativamente estreita, em termos de aspectos fundamentais do produto (tratamos aqui sempre de rodas, embora de tamanhos e algumas características físicas diferentes), e o fato das variantes do produto não afetarem o processo básico de produção. As atividades de produção em massa são também essencialmente repetitivas e amplamente previsíveis. O tipo básico de arranjo físico é a forma geral do arranjo de recursos produtivos da operação. 


\section{Projeto Detalhado do Arranjo Físico}

O projeto detalhado do arranjo físico por produto inclui uma determinada gama de decisões, como por exemplo: tempo do ciclo a que o projeto precisa conformar-se, número de estágios da operação, arranjo dos estágios na linha; tempo de ciclo de cada parte do projeto.

\subsection{Elementos do Planejamento de Espaço}

Todo planejamento de espaço tem quatro elementos fundamentais e dois elementos derivados. Os elementos fundamentais são: Unidades de Planejamento de Espaço (UPEs), afinidades, espaço e limitações. Quando do desenvolvimento de um planejamento de espaço, é necessário definir e especificar inicialmente as UPEs. Em seguida, avaliar as afinidades entre as UPEs. Utilizando as afinidades, avalia-se então as relações entre UPEs para formar um ou mais diagramas de afinidades. $\mathrm{O}$ diagrama de afinidades é o primeiro elemento derivado. $\mathrm{O}$ espaço acrescido ao diagrama de afinidades produz um planejamento primitivo de espaço. As limitações aplicadas ao planejamento primitivo de espaço produzem o planejamento do espaço.

\subsection{Estudo de Tempos}

"O estudo dos tempos destina-se à determinação de um tempo padrão para a execução de cada tarefa, possibilitando o controle de rendimento da mão-de-obra, a apuração dos custos e a instalação de sistemas objetivos de incentivos salariais.” (CHRISTOPHER; THOR, 1993)

O fluxograma vertical é também denominado esqueleto ou mapofluxograma, e é utilizado no estudo de processos produtivos (linha de produção), no qual se pode dividir um grande processo em vários outros mais simples e com poucas áreas envolvidas e um número restrito de operações. A "análise do processo" é a técnica mais freqüentemente utilizada na investigação de métodos. Constitui representação gráfica, em seqüência, de todos os fatos que influem no processamento do elemento analisado. O gráfico de análise do processo representa o fluxo ou andamento do objeto da investigação (CHRISTOPHER; THOR, op. cit.).

O fluxograma vertical nos oferece um registro dos tempos de cada parte das atividades relacionadas ao processo produtivo. Entretanto, surge um problema quando o processo apresenta uma divisão de fluxo, quando a escolha do caminho a ser tomado pela roda, em se tratando do processo de reparo, ou de revisão geral, tem como variável a quantidade de vezes que aquela determinada roda já passou por processos de reparo. Em outras palavras, para que a roda entre na oficina para revisão geral, assume-se que ela precisa ter passado outras quatro vezes na oficina de rodas para reparo. E, o reparo, por sua vez, acontece a cada número determinado de ciclos (considera-se um ciclo, a realização de um pouso mais uma decolagem), variando de modelo para 
modelo de avião. Será necessário, portanto, a elaboração de dois mapofluxogramas, sendo um para o processo de reparos, e outro para o processo de revisão geral, os quais terão como produto foco a roda.

Este estudo é de fundamental importância para se determinar os tempos padrão de cada uma das atividades, e se aglomerar essas atividades dentro das UPE's as quais elas pertencem, para que seja possível a identificação em quanto tempo uma roda percorre cada UPE individualmente, o que já trará reflexões sobre possíveis pontos de gargalo, e possibilidades de redução em transportes e estoques desnecessários.

\subsection{Balanceamento de linha}

O objetivo principal do balanceamento é racionalizar a utilização dos recursos humanos e máquinas dentro de uma unidade produtiva, ou seja, nivelar a utilização dos mesmos com relação aos tempos um determinado processo. O Balanceamento anula os gargalos de produção, e dá o máximo de produtividade, pois elimina as esperas e mantém um ritmo no trabalho de conjunto (TOMPKINS et al, 2003).

Para que seja realizado o balanceamento de linha, é necessário que os tempos de processamento de uma peça de cada UPE já tenham sido coletados, para que se possa a partir destas medições iniciarem a análise dos tempos. Sendo assim, o ao estudo de tempos precede necessariamente o balanceamento de linha. Utilizou-se uma modelagem matemática baseada em redes de filas com buffers ilimitados para representar a situação problema do nosso estudo.

O estudo foi dividido em fases para a melhor orientação do que pretendemos atingir com a distribuição dos recursos de mão-de-obra disponíveis:

- Definição do problema, nesta etapa pretende-se identificar com clareza quais são os objetivos a serem alcançados, qual é a situação atual mensurada do processo e quais são as restrições oferecidas;

- $\quad$ Formulação do Modelo, o modelo permitirá um melhor entendimento das características dos objetos de decisão reais, através da simplificação das variáveis existentes;

- Análise do desempenho do sistema, através de simulações realizadas com auxílio de planilha eletrônica, pode-se projetar os resultados esperados com as modificações propostas; interpretação dos resultados, a partir dos resultados obtidos com as simulações, para então definir para o nosso problema qual será a melhor alternativa.

- $\quad$ Estudo de caso

Os dados coletados foram organizados conforme a aplicação dos conceitos apresentados na seção anterior. Serão descritas todas as informações coletadas a respeito das diversas características de um projeto de layout. 


\subsection{Mão-de-obra}

A mão-de-obra utilizada é de um total de 16 pessoas atuando em atividade operacional, mais quatro pessoas atuando no escritório da Oficina. Das 16 pessoas atuantes na operação, quatro delas são inspetores, os quais trabalham apenas nas atividades de testes não destrutivos. Sendo assim, restam-nos 12 empregados atuando diretamente nas demais operações, dividindo o $\mathrm{HH}$ da oficina em: 96HH/dia à disposição da produção; 32HH/dia à disposição para Testes Não Destrutivos; 32HH/dia à disposição para atividades administrativas e de supervisão.

\subsection{Demanda de serviço}

Foi feita uma busca no sistema por todas as rodas entregues pela oficina nos meses de dezembro e janeiro, e chegou-se a uma demanda média no mês de dezembro de 18,9 rodas/dia, e no mês de janeiro de 13,56 rodas/dia. Para efeito deste estudo será utilizada a média aritmética dessas duas médias, chegando a um valor aproximado de 16,5 rodas/dia, das quais aproximadamente $1 / 5$ entra na oficina para revisão geral e 4/5 entram na oficina para reparos.

\subsection{Maquinário e ferramental utilizado}

Segue uma lista detalhando o maquinário e ferramental: Elevador de carga - 1 - localizado no recebimento; descolador de pneus - 2 - localizados na desmontagem; pistolas desaparafusadoras de ar comprimido - 4 - móveis mas localizadas na desmontagem e na montagem; talha - 3 - 1 localizada na desmontagem, 1 localizada na lavagem e 1 localizada na montagem; jato de Granalha plástica - 1 - localizada na lavagem; bandeja de Lavagem com Querosene - 1 - loacalizada na lavagem; estufa secadora - 2 - 1 localizada na lavagem e 1 localizada na inspeção por líquido penetrante; lavagem química de componentes - 1 - localizada na lavagem; jato de pó químico revelador -1 - localizado na inspeção por líquido penetrante; pistola de luz - 1 - utilizada na inspeção por líquido penetrante; equipamento de Inspeção por correntes parasitas - 1 - localizado na inspeção por correntes parasitas; torquímetro elétrico - 1 - localizado na área de torque; posicionador de semicubos - 3 - localizados na área de torque; engraxador de rolamentos - 1 localizado na inflação; painel de Nitrogênio - 1 - localizado na inflação; gaiola protetora para inflação - 2 - localizadas na inflação. 


\section{Resultados}

\subsection{O processo produtivo}

Os estoques de pequenas peças, como pastilhas, parafusos, etc. permanecem no almoxarifado. Toda solicitação é feita através do sistema e um funcionário da oficina de rodas e freios, de posse do número da reserva gerado pelo sistema vai até o balcão do almoxarifado buscar a peça solicitada, o almoxarifado expede então a nota e libera a peça para a oficina de rodas e freios. Os níveis de estoque atuais podem ser visualizados pelo sistema, o que se bem utilizado pode gerar uma previsão. As rodas provenientes diretamente do hangar não têm nenhuma previsibilidade de tempo e demanda, dificultando a atividade regular.

A oficina trabalha baseada nas prioridades definidas pelo nível de estoque das rodas no Estoque Rio (almoxarifado). Entretanto esse nível de estoque nem sempre é posicionado para a oficina, gerando incerteza. A oficina também desconhece quais seriam os níveis de estoque adequados, como estoque médio, estoque de segurança, etc.

No caso das rodas usadas, quando retiradas do avião no local da oficina, estas seguem através do grupo de apoio de manutenção diretamente para a oficina de rodas e freios. Quando provenientes de outras bases ao redor do mundo, as rodas chegam no setor de cargas da área industrial, são trazidas pelo setor de recebimento e expedição, e encaminhadas à oficina de rodas e freios. Para as rodas consideradas $o k$ para uso, quando provenientes do próprio local da oficina, o mesmo caminhão que leva as rodas usadas, aproveita em uma única viagem diária para carregar as rodas $o k$ para o setor de recebimento e expedição, as quais posteriormente vão para o almoxarifado. No caso de troca local no hangar, o próprio setor de manutenção solicita e vai buscar a roda $o k$ no almoxarifado. O almoxarifado pode também receber solicitação via radio da área industrial do Rio de Janeiro, a qual o setor de recebimento e expedição se encarrega de transportar com o caminhão.

Quando a solicitação é proveniente de outras bases, a própria base solicita ao almoxarifado via sistema, esse setor então prepara a documentação e leva o pedido ao setor de recebimento e expedição, que encaminha ao setor de cargas para ser enviado.

\subsection{O Fluxograma}




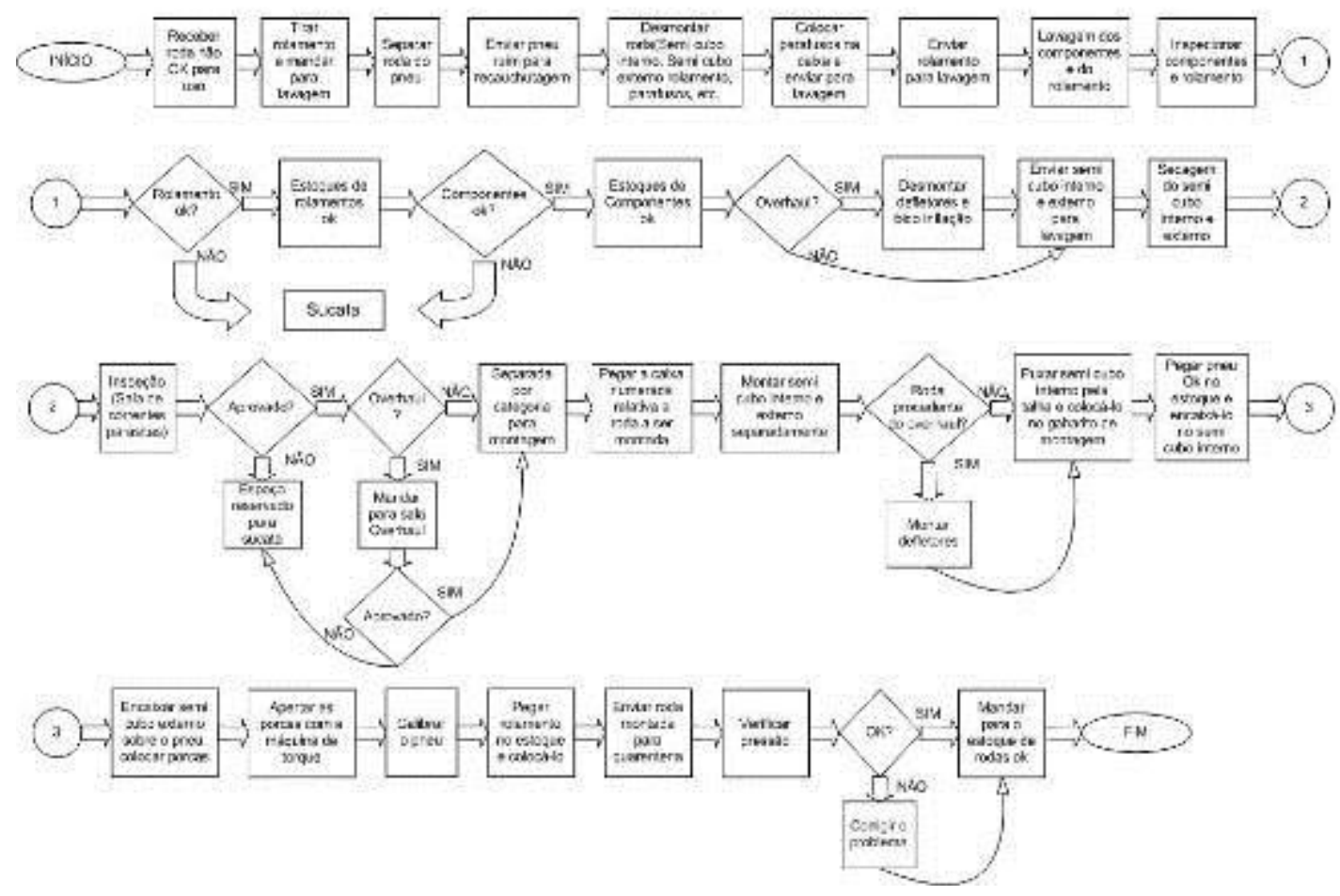

\subsection{O Lay-Out}

A metodologia utilizada é conhecida como Planejamento Sistemático de Layout (SLP), descrita em Muther (1978). Abaixo apresentaremos as etapas propostas por esse método:

\section{- Diagrama das Relações}

O diagrama das relações evita a necessidade de memorizar as decisões e razões para elas, garante a consistência das relações e a capacidade de substanciar e rever o que fizemos, além de servir como uma folha de verificação conveniente, evitando que deixemos de colocar alguma relação que deva ser incluída em nosso planejamento, conforme Figura 2. 
Figura 2 - Diagrama de relações entre os setores da oficina

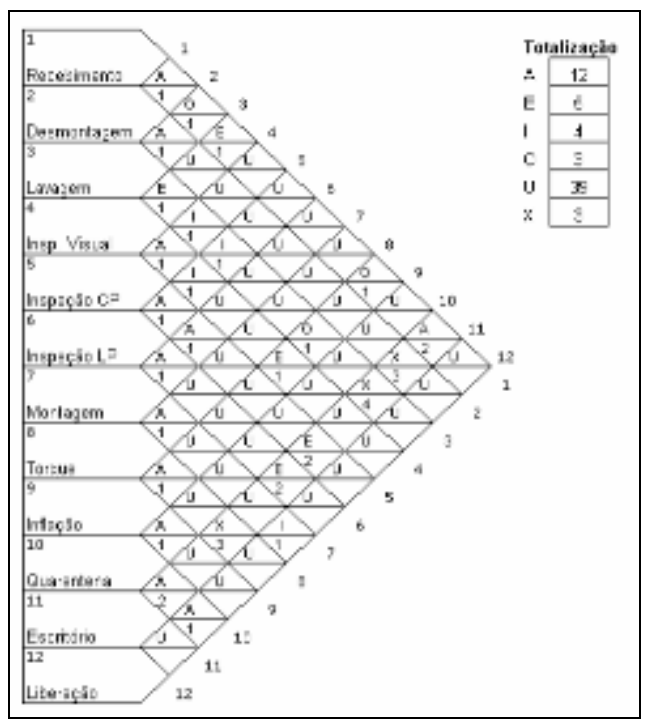

- $\quad$ Estabelecimento das Necessidades de Espaço

Estabeleceu-se para cada atividade: A área necessária, as características físicas, as utilidades (água, luz, gás, etc.); e quaisquer restrições na configuração. Utilizando então a mesma lista de UPEs do primeiro passo, determinou-se e se registrou o espaço para cada atividade. A classificação utilizada para dar prioridade às principais necessidades daquela determinada UPE segue o mesmo formato utilizado anteriormente, atribuindo vogais de A até O. Dessa maneira, integrou-se o planejamento com as considerações práticas envolvidas na construção, conforme Figura 3.

Figura 3 - Tabela de necessidades de espaço da oficina de rodas e freios

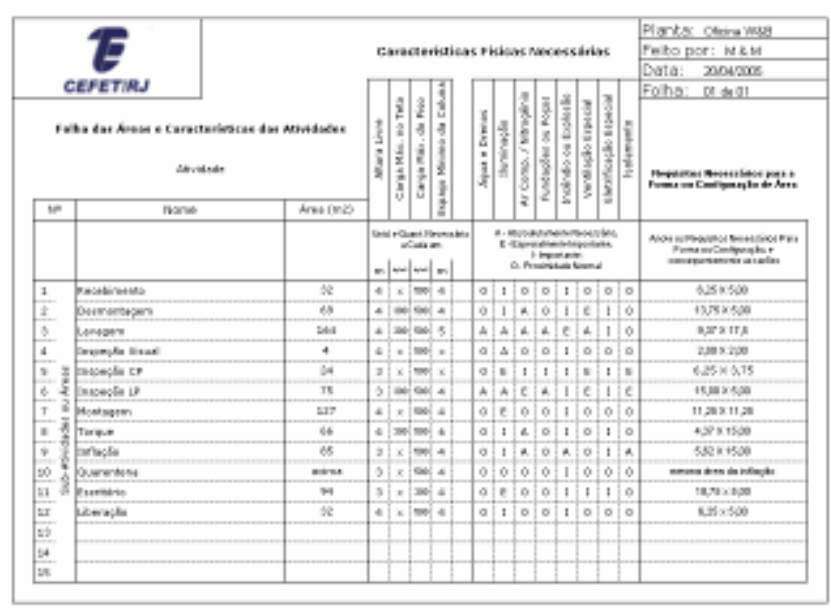

\section{- $\quad$ Relações das Atividades no Diagrama}

Utilizou-se símbolos que representem cada atividade, nesse caso números. Utilizou-se ainda um código de linhas: Vermelha indicando relações A; azul indicando relações E; verde indicando relações I; pretas indicando relações $\mathrm{O}$; e pretas em pontilhado indicando relações $\mathrm{X}$. Cada uma 
indicará o grau de proximidade de cada UPE. A partir daí serão criadas livremente diversas situações de posicionamento das UPEs, de modo a buscar o melhor arranjo possível, o mais próximo possível do arranjo ideal. Posteriormente foi desenhado, em arranjo físico, as relações desejadas e previamente registradas no diagrama, conforme Figuras $4 \mathrm{a}$ e $4 \mathrm{~b}$.

Figura 4 - Diagrama de relação entre as tarefas para duas alternativas

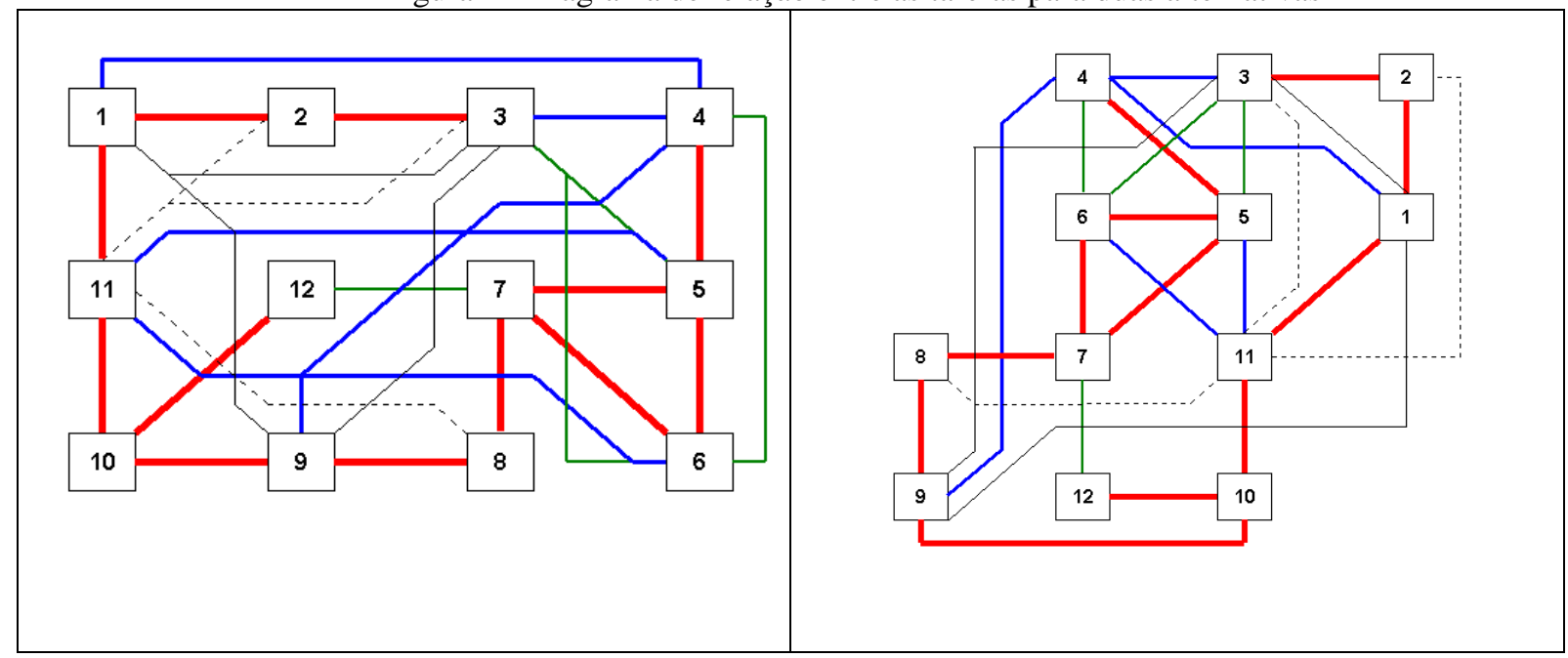

\section{- Desenho dos Layouts de Relação de Espaços}

Este passo consiste em integrar visual e graficamente ao espaço físico as relações apontadas no passo anterior. Nessa etapa são feitos os arranjos necessários para ajustar todas as considerações de modificação.

Estabeleceu-se então uma escala adequada, para a planta, que permita mostrar o plano inteiro em uma folha, e redistribuiu-se as UPEs até integrá-las às condições de modificações e às características físicas. Deve ser desenvolvido num primeiro momento o arranjo de espaços ideal. Em seguida, deve ser trabalhado um arranjo realístico, com a mínima variação possível do ideal.

\section{Avaliação dos arranjos}

Será identificado cada arranjo alternativo, estabelecido todos os fatores, considerações ou objetivos pertinentes que afetam a escolha da melhor alternativa, atribuído para cada fator um valor de peso, indicando assim sua importância relativa para a eficiência do layout, classificando cada plano alternativo para cada fator.

\subsection{Detalhamento do plano de layout}

Esta é a etapa final do projeto de layout. Nela é desenhado o plano de layout selecionado e marcado de forma significativa os equipamentos ou características detalhadas individuais. O plano completo poderá então ser utilizado para orientar a instalação (Figura 5). 
Figura 5 - Layout modificado

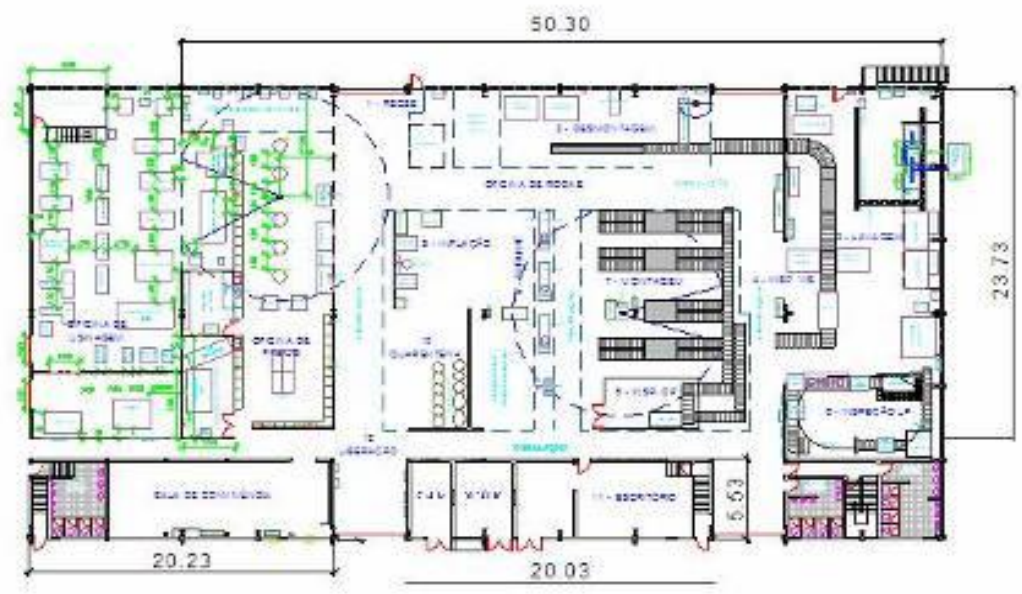

\subsection{Unidades de Planejamento de Espaço (UPEs)}

Foram adotas as seguintes divisões, que deram origem às unidades de planejamento de espaço a serem adotadas: Recebimento, desmontagem, lavagem, inspeção visual, inspeção por correntes parasitas, inspeção por líquido penetrante, montagem, torque, inflação, quarentena, escritório, liberação.

Serão apresentadas as três proposições, adequadas ao espaço da oficina, conforme Figuras 6, 7 e 8.

Figura 6 - Proposição de layout \#1

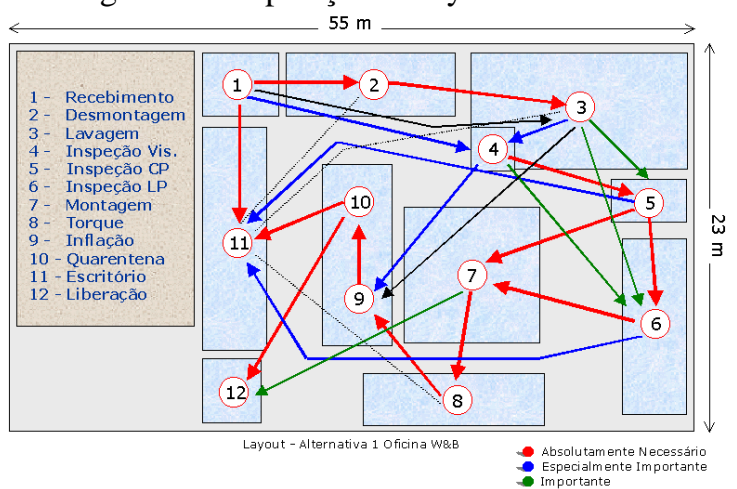

Figura 7 - Proposição de layout \#2

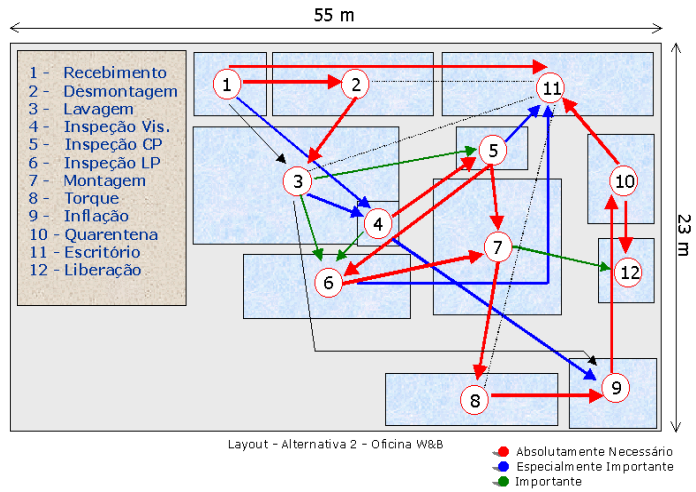


Figura 8 - Proposição de layout \#3

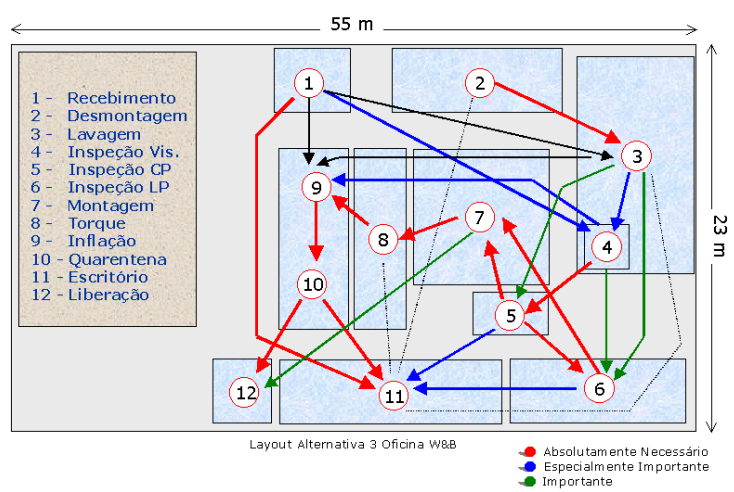

Comparando-se as alternativas, incluindo o layout atual, tomando como base os seguintes critérios: Favorecer o fluxo, diminuir deslocamentos, evitar cruzamentos, melhor espaço livre, facilitar supervisão, investimento mínimo, expansibilidade, aproveitamento das condições naturais, aparência. Após o somatório e pontos obtidos por cada alternativa, observou-se que a alternativa 3 é a que apresenta um melhor desempenho.

Quadro 1 - Quadro comparativo das alternativas de layout

\begin{tabular}{|l|l|l|l|l|}
\hline & \multicolumn{5}{|l|}{ Alternativas } \\
\hline Características & Atual & 1 & 2 & 3 \\
\hline Espaço percorrido pelo produto & $105,7 \mathrm{~m}$ & $109,9 \mathrm{~m}$ & $94,28 \mathrm{~m}$ & $85,71 \mathrm{~m}$ \\
\hline Quantidade de UPE's remanejadas & 0 & 7 & 9 & 3 \\
\hline Cruzamentos em fluxos principais & 6 & 0 & 1 & 2 \\
\hline
\end{tabular}


Quadro 2 - Tabela de avaliação das alternativas de layout

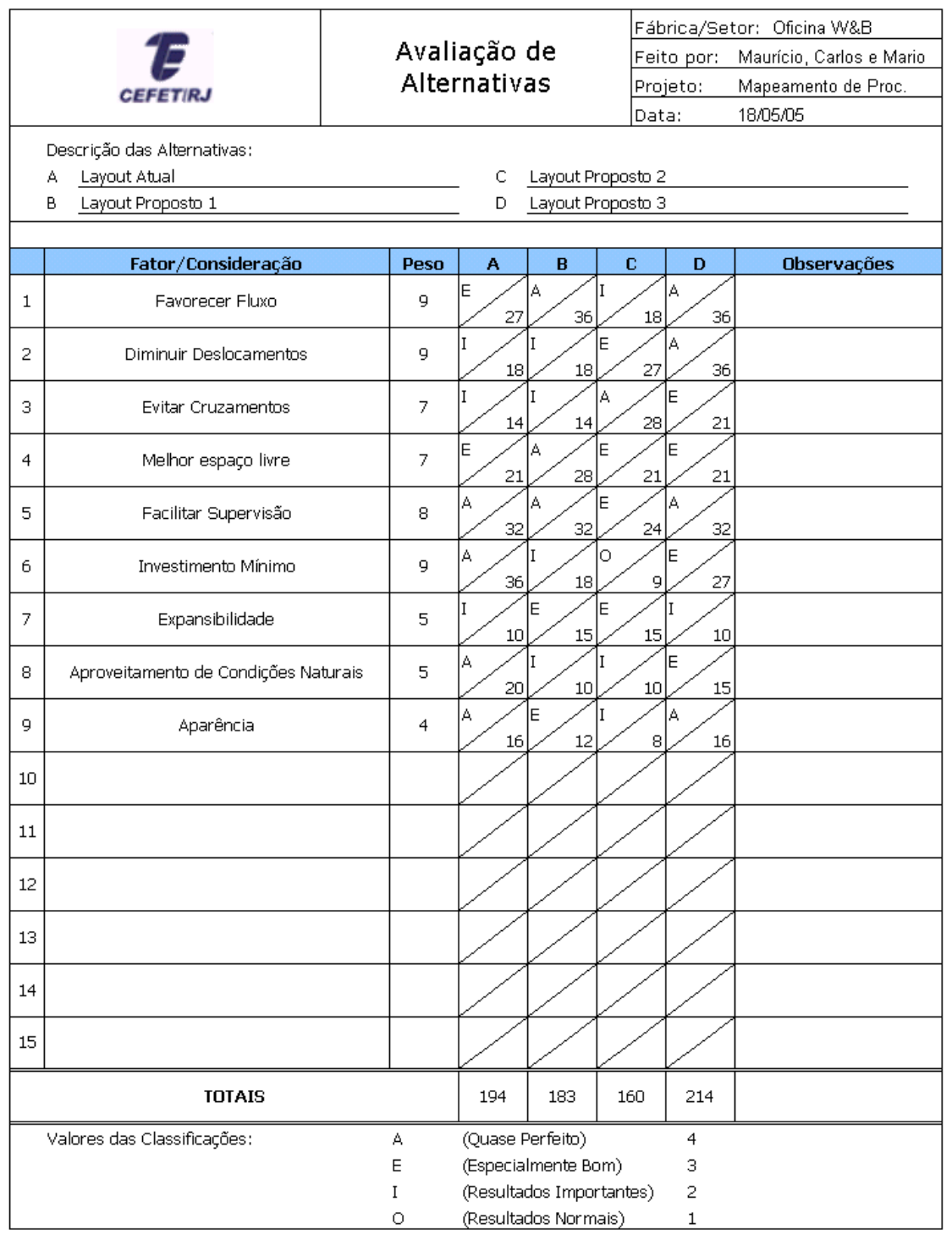

\subsection{O Estudo de Tempos}

Os conjuntos de medições de tempo estão organizados por cores diferentes. Isso porque estas cores já indicam as divisões dos conjuntos de tempos em duas UPE's, de modo a facilitar a análise futura dos dados (Figura 9). 
Figura 9 - Resultado sumarizado do estudo de tempos e movimentos

\begin{tabular}{|l|c|c|c|c|c|}
\hline \multicolumn{1}{|c|}{ Setor } & $\begin{array}{c}\text { Núm. } \\
\text { Homens } \\
\text { utilizados no } \\
\text { momento }\end{array}$ & $\begin{array}{c}\text { Cap. } \\
\text { Disponivel } \\
\text { HH diária }\end{array}$ & $\begin{array}{c}\text { Cap. } \\
\text { roda/home } \\
\text { m }\end{array}$ & $\begin{array}{c}\text { Cap. } \\
\text { Retificada } \\
\text { HH Diária }\end{array}$ & $\begin{array}{c}\text { Utilizada HH } \\
\text { diário } \\
\text { P/16,5 } \\
\text { rodas/dia }\end{array}$ \\
\hline Desmontagem & 2 & 16 & $0: 21: 07$ & 12,8 & $5: 48: 26$ \\
Lavagem & 1 & 8 & $0: 06: 00$ & 6,4 & $1: 39: 00$ \\
Lavagem Overhaul & 1 & 8 & $0: 12: 50$ & 6,4 & $0: 42: 21$ \\
Secagem & 1 & 8 & $1: 30: 10$ & 6,4 & $24: 47: 45$ \\
Inspeçăo CP & 1 & 8 & $0: 01: 10$ & 6,4 & $0: 19: 15$ \\
Inspeção Overhaul e Componentes & 2 & 16 & $1: 31: 40$ & 12,8 & $5: 02: 30$ \\
Montagem & 6 & 48 & $00: 24: 30$ & 38,4 & $6: 44: 15$ \\
Inflação & 2 & 16 & $0: 22: 50$ & 12,8 & $6: 16: 45$ \\
\hline ToTaIS & 16 & 128 & & 102,4 & $51: 20: 17$ \\
\hline
\end{tabular}

Obs: Nẫo está sendo levado em consideraçẫo o turno da tarde, que tem mais 4 funcionários $(32 \mathrm{HH})$

Teoria

$50 \%$ de Utilizaçẫo $\mathrm{HH}$

$70 \%$ de utlizaçẫo $\mathrm{HH}$

$80 \%$ ou maior de utilizaçẫo $\mathrm{HH}$
Setor sem organizaçã̃o do trabalho, sem balanceamento e sem metas

Setor em que alguns métodos de trabalho já estẫo estabelecidos

Setor com metas definidas e com processos de trabalho definidos

Devido à existência de gargalos no processo produtivo e da falta de uma melhor distribuição das atividades e do maquinário e uma melhor programação dos serviços, é utilizado aproximadamente apenas cinqüenta por cento do homem-hora disponível.

\section{Análise de gargalos através de redes de filas}

Após a avaliação do layout aplicando-se o SLP, conforme descrito anteriormente, o sistema foi modelado como uma rede de filas em série para se analisar as esperas e os gargalos. Uma vez de posse do layout proposto foram analisados 7 (sete) postos de trabalho representando de forma agrupada todo o fluxo da oficina em estudo, conforme Quadro 3.

Quadro 3 - Descrição dos postos de trabalho e seus respectivos tempos de processamento

\begin{tabular}{|l|c|c|}
\hline \multicolumn{1}{|c|}{ UPE } & Codificação & $\begin{array}{c}\text { Tempo de } \\
\text { processamento }\end{array}$ \\
\hline Desmontagem & $\mathrm{D}$ & $\operatorname{Exp}(14,08) \mathrm{min}$ \\
\hline Lavagem & $\mathrm{L}$ & $\operatorname{Exp}(03,00) \mathrm{min}$ \\
\hline Secagem & $\mathrm{S}$ & $\operatorname{Exp}(30,00) \mathrm{min}$ \\
\hline Inspeção CP & $\mathrm{C}$ & $\operatorname{Exp}(01,17) \mathrm{min}$ \\
\hline Montagem & $\mathrm{M}$ & $\operatorname{Exp}(09,34) \mathrm{min}$ \\
\hline Torque & $\mathrm{T}$ & $\operatorname{Exp}(34,67) \mathrm{min}$ \\
\hline Inflação & $\mathrm{I}$ & $\operatorname{Exp}(22,83) \mathrm{min}$ \\
\hline
\end{tabular}


O modelo foi implementado para a realização da simulação, com o auxílio de planilhas eletrônicas e algumas rotinas de cálculos foram desenvolvidas. Os resultados foram os seguintes:

a) Para o tempo de uma semana:

Entrada de rodas na oficina: 16,5 rodas $/$ dia $=0,034375$ rodas $/$ minuto

Número de máquinas em paralelo:

\begin{tabular}{|l|c|cc|}
\multicolumn{1}{|c|}{ Quadro 4 - Número de máquinas em paralelo para a simulação da oficina } \\
\hline UPE & Codificação & $\begin{array}{c}\text { Máquinas em } \\
\text { paralelo } \\
\text { (Mínimo) }\end{array}$ & $\begin{array}{c}\text { Máquinas em } \\
\text { paralelo } \\
\text { (Máximo) }\end{array}$ \\
\hline Desmontagem & $\mathrm{D}$ & 2 & 6 \\
\hline Lavagem & $\mathrm{L}$ & 1 & 2 \\
\hline Secagem & $\mathrm{S}$ & 1 & 1 \\
\hline Inspeção CP & $\mathrm{C}$ & 1 & 2 \\
\hline Montagem & $\mathrm{M}$ & 2 & 2 \\
\hline Torque & $\mathrm{T}$ & 2 & 1 \\
\hline Inflação & $\mathrm{I}$ & & 2 \\
\hline
\end{tabular}

Os resultados podem ser vistos na Figura 10, para o número mínimo de máquinas em paralelo e na Figura 11, para o número máximo de máquinas em paralelo.

Figura 10 - Resultados da simulação. em (a) 91 rodas forma processadas em 1 semana e 16 não conseguiram ser trabalhas; em (b) vê-se claramente a identificação do gargalo no posto 3

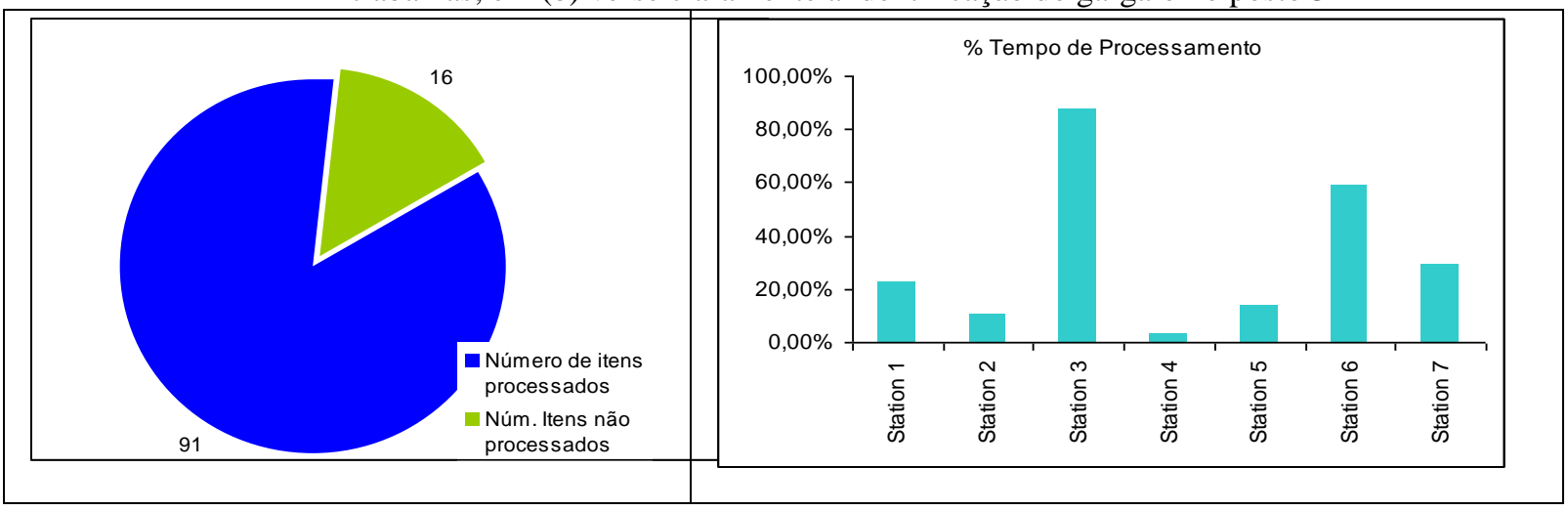

$\mathrm{Na}$ Figura 11, pode-se notar que o aumento significativo no número de máquinas em paralelo não é suficiente para um aumento da produtividade da oficina, pois o gargalo continua sendo o posto de número 3 . 
Figura 11 - Resultados da simulação. em (a) 92 rodas forma processadas em 1 semana e 15 não conseguiram ser trabalhas; em (b) vê-se claramente a identificação do gargalo no posto de trabalho 3, que ainda influencia o desempenho do sistema como um todo

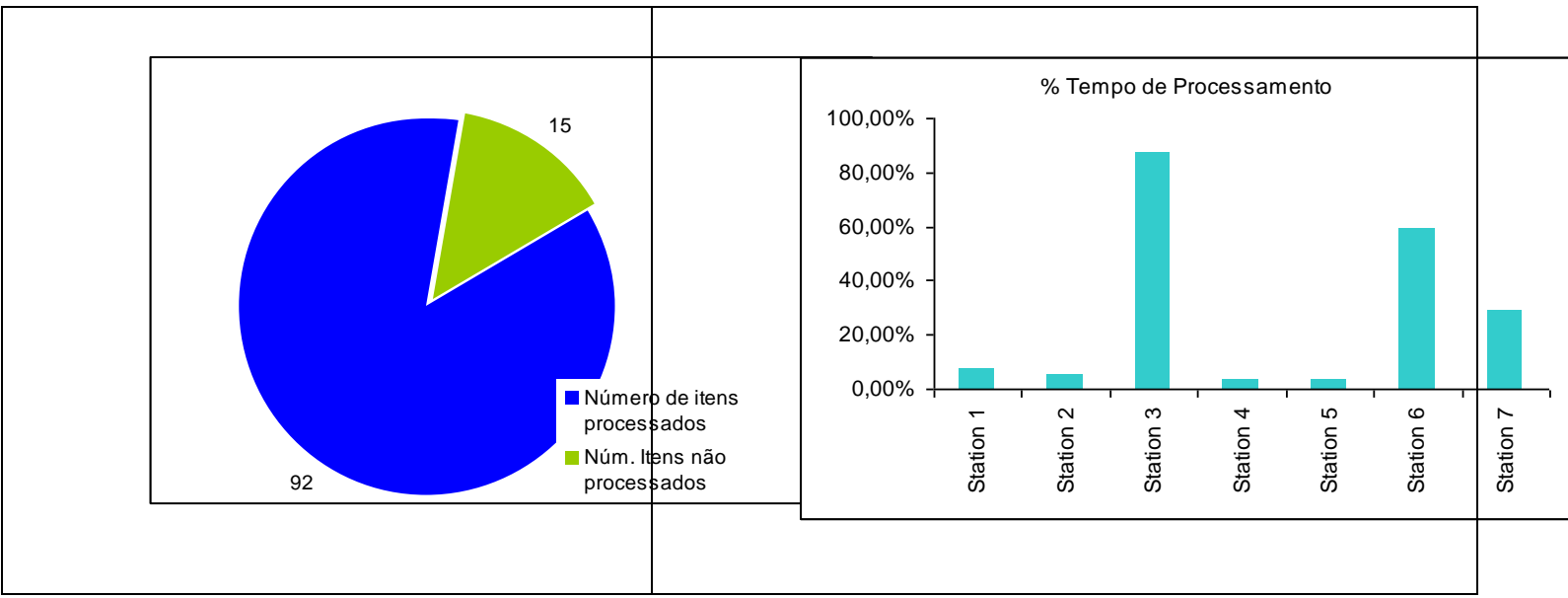

\section{Conclusões}

Foi observado que ao tratar-se de uma instalação já existente, a modificação do arranjo físico deve ter sempre como elemento balisador as limitações impostas pela edificação. Isso auxiliará no sentido de trazer as oportunidades de melhoria para o campo da viabilidade.

Algumas etapas durante o estudo demonstraram-se bastante importantes sendo objeto de grande atenção do planejador de espaço ao utilizar esse tipo de abordagem. Trata-se das etapas um, dois e cinco, que são respectivamente: Determinação dos relacionamentos, determinação das necessidades de cada UPE e avaliação dos arranjos. Qualquer erro cometido em uma dessas etapas poderá resultar em distorções graves na elaboração do arranjo final.

A nova planta propõe redução de cruzamentos de fluxo de materiais, redução do espaço total percorrido e aproximação de UPE's afins. Aproximamos as inspeções, o que é vantajoso pelo fato delas utilizarem a mesma mão-de-obra, não necessitando de deslocamento de pessoas, e evitando a necessidade que se tinha no layout anterior de se transportar as rodas em um carrinho até a inspeção líquido penetrante.

O principal ponto forte da abordagem adotada é a simplicidade de aplicação e análise.

Com o auxílio da metodologia de simulação de redes de filas, foi possível a análise e identificação dos gargalos do sistema e a proposição de um cenário adicional baseado na realidade operacional da oficina foi útil para se comprovar que é inócuo a aplicação de recursos em postos de trabalho que não sejam o gargalo do sistema.

\footnotetext{
Abstract

This work aim to analyze the application of SLP - systematic planning layout conjugate with queueing theory to complement a well-established methodology. A readjustment layout project was carried out in a wheel and brakes workshop, objecting to evaluate the proposed technique. Using a real case study, it has been possible to identify the resources which limit the workshop capacity, concluding that, as with the increase in non-critical resources the overall
} 
capacity of the workshop do not reach the acceptable values. The resource efforts must be made on the bottleneck pointed out by the methodology.

Key-words: workshop, layout optimization, SLP, queueing theory.

\section{Referências}

CHIN, S.Y.; G. F. E. V. Detalhamento das fases para o desenvolvimento de um layout do tipo job-shop para fins de estudo em modelagem e simulação. Revista Gestão Industrial, v. 4, n. 4, p. 176-203, 2008.

JÚNIOR, J. H. C. G.; FILHO, E. V. G. Análise de desempenho dos arranjos físicos distribuídos operando sob roteamento de peças com flexibilidade de seqüenciamento. Revista Gestão Industrial, v. 3, n. 1, p. 01-12, 2007.

CHRISTOPHER, W. F.; THOR, C. G. Handbook of productivity measurement and improvement. Portland Productivity, 1993

HILLIER, F. S.; LIEBERMAN, G. J. Introduction to operations research. New York: McGraw Hill, 2001.

LEE QUARTERMAN, T. Projeto de instalações e do local de trabalho. São Paulo: IMAM, 1998.

MARUJO, L. G. Otimização da logística multimodal de um cd utilizando o PQA. In: SIMPÓSIO BRASILEIRO DE PESQUISA OPERACIONAL, 42, 2009, Porto Seguro. Anais... Porto Seguro: SBPO, 2009.

MUTHER, R. Planejamento do layout: sistema SLP. São Paulo : Edgard Blücher, 1978.

SLACK, N.; CHAMBERS, S.; JOHNSTON, R. Administração da produção. São Paulo: Atlas, $2^{\circ}$ ed. 2002.

TOMPKINS, J. A.; WHITE, J. A.; BOZER, Y. A.; TANCHOCO, J. M. A. Facilities planning. USA: John Wiley \& Sons, 3rd edition, 2003.

\section{Dados dos Autores:}

Nome completo: Lino G. Marujo

Filiação institucional: CEFET-RJ Departamento: Depto. de Engenharia de Produção

Função ou cargo ocupado: Professor

Endereço completo para correspondência (bairro, cidade, estado, país e CEP):

Av. Maracanã, 229, Bl E, 1o andar, Rio de Janeiro, RJ, Brasil, CEP: 20271-110. Telefones para contato: (21) 2566-3015

e-mail:linomarujo@cefet-rj.br

Nome completo: Diego Carvalho

Filiação institucional: CEFET-RJ Departamento: Depto. de Engenharia de Produção

Função ou cargo ocupado: Professor

Endereço completo para correspondência (bairro, cidade, estado, país e CEP):

Av. Maracanã, 229, B1 E, 1o andar, Rio de Janeiro, RJ, Brasil, CEP: 20271-110. Telefones para contato: (21) 2566-3015

e-mail: dcarvalho@ieee.com 
Nome completo: Mauricio N. Leitão

Filiação institucional: CEFET-RJ Departamento: Depto. de Engenharia de Produção

Função ou cargo ocupado: Mestrando

Endereço completo para correspondência (bairro, cidade, estado, país e CEP):

Av. Maracanã, 229, Bl E, 1o andar, Rio de Janeiro, RJ, Brasil, CEP: 20271-110. Telefones para contato: (21) 2566-3015

e-mail:mnleitao@gmail.com

Recebido para publicação em: 23/09/2010

Aceito para publicação em: 29/11/2010 